\title{
Gender Difference, Nutritional Supplements and Drug use in Sport to Enhancing Performance: an Italian Revision over the Last Decade
}

\author{
Filomena Mazzeo', Stefania Santamaria' and Pietro Montesano ${ }^{2}$ \\ 'University of Naples "Parthenope", Department of Science and Technology, Naples, Italy, 2University of Naples "Parthenope”, Department of Sport \\ Sciences and Wellness, Naples, Italy
}

\begin{abstract}
In last years, there has been a multitude of studies on doping, such as in recreational and in amateur sport. The extent of this phenomenon was clarified for special populations (like e.g. bodybuilders) and for special substances (mostly for anabolic steroids). Doping is present in sportsmen and women; the reasons why may be many and various. The aim of this study is to discover the gender disparity of drugs addiction as doping practice and breakdown by sport bodies and gender. The data show the anti-doping test took place on Italian professional athletes during the last years: from 2007 to 2017. Data showed are originated from the report commissioned by the Italian Ministry of Health. About checked doped athletes there are significant gender differences in doping attitude and/or in doping profiling. First of all, males seem to be more exposed to doping than females. The prohibited substances most frequently used by females athletes are diuretics and masking agents (10 athletes in 2014), cannabinoids (5 in 2007) and stimulants (5 in 2011) compared to males athletes who use mostly anabolic agents (27 in 2017), cannabinoids (20 in 2012) and diuretics and masking agents (17 in 2011 e 2014). The addiction of doping substances, depends on various factors related to gender, but what drives men and women is the sense of gratification and ego orientation. Nowadays a significant number of women joined official and Olympic competitions. Doping to enhance female sport performances took importance from the two last decades of the past century.
\end{abstract}

Key words: drugs, illicit substances, sport, gender, anti-doping controls, anti-doping programme

\section{Introduction}

Since ancient times, men have tried to improve their performance. The reasons have changed over time. In the past, in fact, man tried to get better results in hunting. Subsequently, with the birth of fighting and competitions, the goal was to achieve greater economic profits (Mazzeo, 2016).

At the beginning, the substances used had natural or animal origins. Indeed, the Greek wrestlers and the Roman gladiators attempted to improve their own performance by taking mixtures of various types of plants or by eating sheep's testicles (Mazzeo \& Raiola, 2018). But over time, artificial substances and methods were also used (Sjoqvist, Garle, \& Rane, 2008; Thevis \& Scanzer, 2014). In fact, the doping's stakeholders ha- ve always been able not only to identify new substances and new methods but also to steal the new scientific discoveries aimed at the treatment of diseases, for their illegal purposes (Council of Europe, 1989). Doping is a big dimension problem due to the extensive connections between the people involved in the network. It involves the whole society (Mazzeo et al., 2018): not only elite athletes but amateurs too, their friends and relatives, the medical staff, manager, chemists, biologists and pharmacists, pharmaceutical industries, clandestine laboratories, and criminal organizations (Møller \& Dimeo, 2014; Marclay, Mangin, Margot, \& Saugy, 2013; Mazzeo et al., 2018). Moreover, it includes "ordinary people" too who dope for recreational or aesthetic purposes (Thevis \& Scanzer, 2014).

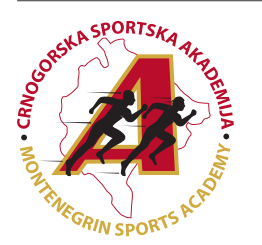

Correspondence:

F. Mazzeo

University of Naples "Parthenope", Department of Science and Technology, Naples, Italy

E-mail: filomena.mazzeo@uniparthenope.it 
In the early 1900s it was realised the doping's dangerousness. In 1928, in fact, the International Association of Athletics Federations became the first International Sport Federation to ban the use of stimulating substances (Valkenburg, de Hon, \& van Hilvoorde, 2014) and in 1968 drug tests were introduced at the Olympic Winter Games in Grenoble and in Olympic Games in Mexico (Kayser, Mauron, \& Miah, 2005; Botrè, 2008). The ban on doping substances and the introduction of anti-doping tests have certainly represented an important tool for the fight against doping but this was not enough (Dvorak et al., 2014). It was necessary create an independent organization with the sole purpose to defeat the doping in the sport (WADA, 2010; Mazzeo et al., 2018; Overbye, Knudsen, \& Pfister, 2013). For this reason, in 1999, it was created the World Anti-Doping Agency (WADA), an international organization, with the aim to promote, coordinate, and monitor the fight against doping in sport in all its forms (Mazzeo et al., 2018; Santamaria, 2016).

In accordance with the WADA Code doping is the presence of a prohibited substance or its metabolites or markers' banned; the use or the attempted use of a prohibited substances or a prohibited method; the refusing or the failing, without compelling justification, to submit to sample collection; the violation of applicable requirements regarding athlete availability for out-of-competition testing; the tampering or the attempting to tamper with any part of doping control; the possession of prohibited substances and prohibited methods; the trafficking or the attempted trafficking in any prohibited substance or prohibited methods; the administration or the attempted administration to any athlete of any prohibited methods or prohibited substances, or the assisting, the encouraging, the aiding, the abetting, the covering up or any other type of complicity involving an anti-doping rule violation or any attempted antidoping rule violation (WADA, 2010). Moreover, WADA has officially listed the banned substances and practices. This list is constantly updated (Mazzeo et al., 2018).

In last years, it is evident that prevalence of studies on doping, focus on recreational and in amateur sport, taking into consideration only certain substance classes or special sport populations. This studies can only provide limited estimates of the prevalence within the total population (Frenger, Pitsch, \& Emrich, 2016).

The early years of the twentieth century are generally represented as a period of triumph for women's sports, with the eventual acceptance of a significant women's programme in the Olympics in 1924 and the proliferation of national organisations for women's sport (Heggie, 2010). So, the desire to win apparently became so pressing for some nations that deliberate and systematic cheating took place in both the men's and women's events. Therefore, doping is present in sportsmen and women; the reasons why may be many and various but doping and gender fraud became central concerns in the late 1950s and 60 s, resulting in the eventual introduction of systematic testing for both at international sporting events in the late 1960s (Heggie, 2010; Mazzeo et al., 2018).

In Italy, doping is banned according to the national Law no. 376/2000 "Regulation of health standards in sports activities and the fight against doping" too. The law established a particular Committee, "Committee for the Monitoring and Control of Doping and the Protection of Health in Sporting Activities", with the main aim of identifying the classes of prohibited substances and the competitions to be monitored, determining the conduct of anti-doping controls, promoting information campaigns for the protection of health in sporting activities and prevention of doping. Since 2003, every year the above mentioned Committee, elaborates and transmits a report containing detailed data on the spread of doping in Italy as well as activities to prevent and combat the phenomenon (Mazzeo et al. 2016a).

The aim of this study was to assess the gender disparity of drugs addiction as doping practice and breakdown by sport bodies and gender.

\section{Methods}

The data show of the anti-doping controls carried out by the Ministry of Health from 2007 to 2017 (www.salute.gov.it). The authors have firstly analysed the data of Italy Anti-doping official website of each single report of the above mentioned Ministry, then they have extrapolated and combined the information on the consumption of doping substances in male and female athletes.

\section{Results}

In Italy, Ministry of Health every year commissions the anti-doping test. Italian legislation provides for only urine tests on athletes (Strano \& Botrè, 2011; Mazzeo et al., 2018). Since 2007 to 2017, 13896 athletes have been checked and 458 were doped corresponding to $3.5 \%$ of the total analysed of which approximately 61 women and 358 men. The majority of controls was carried out in men's competitions. The Commission justified this prevalence with 3 reasons: 1) controls were carried out on minor categories and some sports are practiced by women only in the higher categories; 2) some sports are mainly male; 3 ) often in the calendars of the federations do not appear the place and date of the events and it is therefore difficult to carry out checks (Ministero della Salute, 2008-2018).

As shown in Figure 1, the highest percentage of them is recorded for men in 2010 with $6.3 \%$ and for women in 2015 with $1.9 \%$. The highest number of doped men is recorded in 2010 while for women in the years 2007, 2011, 2012 and 2014. But the difference is considerable, in fact we are talking about 50 men against 8 women.

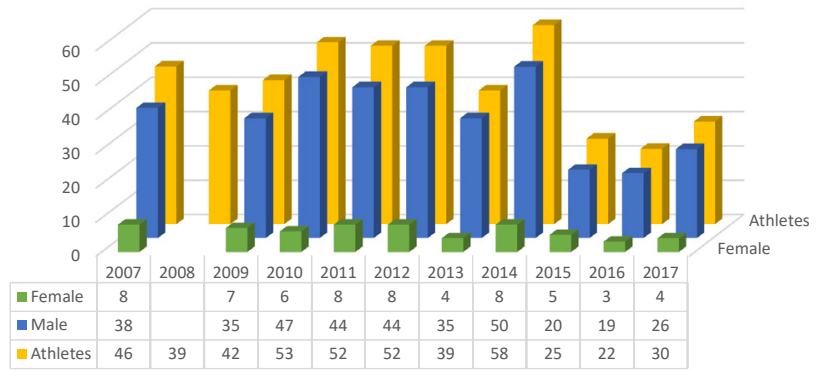

Figure 1. Number of doped athletes from 2007 to 2017 breakdown by gender 
As regards the spread of doping in the various sports analysed, results has shown (Table 1) that cycling is the sport most affected and in particular by men. In reality, in 2011 and 2013, 25 and 19 men were listed against only 2 women. Football and rugby also record relatively high numbers. In fact, the men doped in the aforementioned sports amount to 7 respectively in 2007 and 2012. The number of women doped in various sports, in the various years is insignificant. The highest number is 2 recorded in cycling $(2011,2012,2013)$, in track and field (years 2011 and 2016) and in rugby (year 2012) (Table 1).

Table 1. Number of doped athletes from 2007 to 2017 breakdown by sport bodies and gender

\begin{tabular}{|c|c|c|c|c|c|c|c|c|c|c|c|c|c|c|c|c|c|}
\hline \multirow{2}{*}{ Sports Bodies 2007-2017 } & \multicolumn{2}{|c|}{7} & \multirow{2}{*}{ 8-10 } & \multicolumn{2}{|c|}{11} & \multicolumn{2}{|c|}{12} & \multicolumn{2}{|c|}{13} & \multicolumn{2}{|c|}{14} & \multicolumn{2}{|c|}{15} & \multicolumn{2}{|c|}{16} & \multicolumn{2}{|c|}{17} \\
\hline & $\mathbf{M}$ & $\mathbf{F}$ & & $\mathbf{M}$ & $\mathbf{F}$ & $\mathbf{M}$ & $\mathbf{F}$ & $M$ & $\mathbf{F}$ & $\mathbf{M}$ & $F$ & $\mathbf{M}$ & $\mathbf{F}$ & $\mathbf{M}$ & $\mathbf{F}$ & $\mathbf{M}$ & $\mathbf{F}$ \\
\hline AICS & 2 & 0 & & & & & & & & & & & & & & & \\
\hline ASI & 1 & 0 & & & & & & & & & & & & & & & \\
\hline $\mathrm{ACl}$ - Car racing & 0 & - & & & & & & & & & & & & & & & \\
\hline C.N.S. Libertas & 0 & 1 & & & & & & & & & & & & & & & \\
\hline CSEN - CrossFit & & & & & & & & & & & & & & & & 3 & 0 \\
\hline FASI - Climbing & 1 & 0 & & & & 0 & 0 & 0 & 0 & & & 0 & 0 & 0 & 0 & 0 & 0 \\
\hline FCl -- Cycling & 6 & 0 & & 25 & 2 & 11 & 2 & 19 & 2 & 0 & 0 & 11 & 1 & 9 & 0 & 11 & 1 \\
\hline Fcrl - Cricket & & & & & & & & & & & & & & & & & \\
\hline FGI - gymnastics & 1 & 0 & & & & 0 & 0 & 0 & 0 & 0 & 0 & 0 & 1 & & & & \\
\hline FIB - bowls & & & & & & & & & & & & & & & & & \\
\hline FIBa-Badminton & 0 & 0 & & & & & & & & & & & & & & & \\
\hline FIBBN Am Body Nat & & & & 1 & 0 & & & 1 & 0 & 1 & 1 & & & & & 0 & 0 \\
\hline FIBiS - Biliards & 0 & 0 & & & & & & & & & & & & & & & \\
\hline FIBS - Baseball \& Softball & 0 & 1 & & 2 & 0 & 3 & 1 & 0 & 0 & 0 & 0 & 2 & 0 & 0 & 0 & & \\
\hline FIC - Rowing & 0 & 0 & & & & & & 1 & 0 & 1 & 0 & 0 & 0 & 0 & 0 & 1 & 0 \\
\hline FICK - Canoe Kajak & 0 & 0 & & 0 & 0 & 0 & 0 & 0 & 0 & 0 & 0 & 0 & 1 & 0 & 0 & 0 & 1 \\
\hline FICSF canoe seat fixed & 0 & - & & & & & & & & & & & & 0 & 0 & 0 & 0 \\
\hline FIDAF - Amer.Football & & & & & & 1 & 0 & 1 & 0 & 0 & 0 & & & & & & \\
\hline FIDAL - track and field & 1 & 1 & & 0 & 2 & 2 & 0 & 0 & 0 & 3 & 1 & 1 & 1 & 2 & 2 & 4 & 1 \\
\hline FIDS - Dance Sport & 0 & 0 & & & & & & 0 & 0 & 0 & 0 & & & 1 & 0 & & \\
\hline FIG - Golf & 1 & 0 & & & & 2 & 0 & 0 & 0 & 1 & 1 & & & & & & \\
\hline FIGC - Football & 7 & 1 & & 2 & 0 & 5 & 1 & 1 & 0 & 0 & 0 & 0 & 0 & 2 & 0 & 3 & 0 \\
\hline FIGH - Handball & 4 & 0 & & 1 & 1 & 1 & 0 & 3 & 0 & 0 & 0 & 1 & 1 & 0 & 0 & 0 & 0 \\
\hline FIGMMA (Marti. Arts..) & & & & & & 1 & 1 & & & 0 & 1 & & & 0 & 0 & & \\
\hline FIGS - Squash & & & & & & & & 0 & 0 & 0 & 0 & & & 0 & 0 & 0 & 0 \\
\hline FIH - Hockey & 1 & - & & 1 & 0 & 1 & 0 & 0 & 0 & & & & & & & & \\
\hline FIHP Hockey \& Skating & 0 & - & & & & & & & & 1 & 0 & & & 0 & 0 & & \\
\hline FIJLKAMJ & 2 & 1 & & & & 1 & 0 & & & 0 & 0 & 1 & 0 & 1 & 0 & 0 & 0 \\
\hline FIKB FIKBMS Kick Box & 0 & - & & & & 0 & 1 & 2 & 1 & 0 & 0 & & & & & & \\
\hline FIM - speedboat racing & 0 & - & & & & & & & & & & & & & & & \\
\hline FIN -Swimming & 0 & 0 & & 1 & 0 & 1 & 0 & 1 & 0 & 2 & 1 & 0 & 0 & 1 & 0 & 0 & 0 \\
\hline FIP - Basketball & 0 & 1 & & & & 1 & 0 & 0 & 0 & 0 & 0 & 2 & 0 & 1 & 0 & 1 & 0 \\
\hline FIPAV - Volleyball & 0 & 1 & & 0 & 1 & 0 & 0 & 0 & 0 & 0 & 0 & 0 & 0 & 0 & 0 & 0 & 0 \\
\hline FIPE - FIPCF Weights... & & & & 2 & 1 & 0 & 0 & 1 & 0 & 0 & 1 & & & & & 0 & 0 \\
\hline FIPL - Powerlifting & & & & & & & & & & & & & & & & 0 & 1 \\
\hline FIPM -Modern Pentathlon & & & & & & & & & & & & & & 0 & 0 & & \\
\hline FIPSAS - Game fishing & 1 & 0 & & 0 & 0 & & & 0 & 0 & 0 & 0 & & & 1 & 0 & & \\
\hline FIR-Rugby & 2 & - & & 2 & 0 & 7 & 0 & 1 & 0 & 1 & 0 & 2 & 0 & 1 & 0 & 1 & 0 \\
\hline FIS -Fencing & 0 & 0 & & 0 & 0 & 0 & 0 & 0 & 0 & 0 & 0 & 0 & 0 & & & 1 & 0 \\
\hline FISB -Bowling & 0 & - & & & & & & 0 & 0 & & & & & & & & \\
\hline FISE - Equestrian sports & 0 & 0 & & & & & & 0 & 0 & & & 0 & 0 & & & & \\
\hline FISG - Ice Sports & 1 & 0 & & 1 & 0 & 1 & 0 & 4 & 0 & 0 & 0 & 0 & 0 & 0 & 0 & 0 & 0 \\
\hline FISI - winter Sports & 0 & 0 & & 3 & 0 & 1 & 0 & 0 & 1 & 0 & 1 & 0 & 0 & & & & \\
\hline FISN - Water skiing & 0 & 0 & & & & & & & & & & & & & & & \\
\hline FIT -Tennis & 2 & 0 & & 1 & 0 & 3 & 2 & 0 & 0 & 0 & 0 & 0 & 0 & 0 & 0 & 0 & 0 \\
\hline FITA - Taekwondo & & & & 0 & 0 & 0 & 0 & 0 & 0 & 0 & 1 & 0 & 0 & 0 & 0 & 0 & 0 \\
\hline FITARCO -Arkery & 0 & 1 & & 1 & 1 & 0 & 0 & 0 & 0 & 3 & 0 & 0 & 0 & & & 1 & 0 \\
\hline FITAV & 0 & - & & & & & & & & 0 & 0 & 0 & 0 & & & & \\
\hline FITeT - Table tennis & 0 & - & & 0 & 0 & 0 & 0 & 0 & 0 & & & & & & & & \\
\hline FITRI -Triathlon & 1 & 0 & & 0 & 0 & 2 & 0 & 0 & 0 & 0 & 0 & 0 & 0 & 0 & 0 & 0 & 0 \\
\hline FIV - Sailing & 1 & - & & & & & & 0 & 0 & 0 & 0 & 0 & 0 & & & & \\
\hline FIWuK - Wushu Kung Fu & 0 & - & & & & & & & & & & 0 & 0 & & & & \\
\hline
\end{tabular}


(continued from previous page)

\begin{tabular}{|c|c|c|c|c|c|c|c|c|c|c|c|c|c|c|c|c|c|}
\hline \multirow{2}{*}{ Sports Bodies 2007-2017 } & \multicolumn{2}{|c|}{7} & \multirow[t]{2}{*}{ 8-10 } & \multicolumn{2}{|c|}{11} & \multicolumn{2}{|c|}{12} & \multicolumn{2}{|c|}{13} & \multicolumn{2}{|c|}{14} & \multicolumn{2}{|c|}{15} & \multicolumn{2}{|c|}{16} & \multicolumn{2}{|c|}{17} \\
\hline & $\mathbf{M}$ & $\mathbf{F}$ & & $\mathbf{M}$ & $\mathbf{F}$ & $\mathbf{M}$ & $\mathbf{F}$ & M & $\mathbf{F}$ & M & $\mathbf{F}$ & $\mathbf{M}$ & $\mathbf{F}$ & $\mathbf{M}$ & $\mathbf{F}$ & $\mathbf{M}$ & $\mathbf{F}$ \\
\hline FMI - Motorcycling & 1 & - & & & & & & & & & & & & & & & \\
\hline FPI-Boxing & 0 & - & & & & & & 0 & 0 & 0 & 0 & 0 & 0 & & & 0 & 0 \\
\hline UISP (Italian Sport for all) & 1 & 0 & & 0 & 0 & & & & & 0 & 0 & & & & & & \\
\hline UITS - shooting gallery & 1 & 0 & & & & & & & & 4 & 0 & & & & & & \\
\hline U.A. ACLI & & & & 1 & 0 & & & & & & & & & & & & \\
\hline WABBA - world amat. BB & & & & & & & & & & & & & & 0 & 1 & & \\
\hline
\end{tabular}

As concern the consumption of prohibited substances, over the year there is a difference between men and women. First of all, the data show a high consumption of doping substances in men instead of in women. In particular, men take more cannabinoids, stimulants, diuretics and other masking agents, anabolic agents and hormones. In 2017 there was the highest number of men who took a substance: 27 athletes, in fact, took anabolic steroids. Different speech for women. In fact, for them there are irrelevant data with the exception of 2014 in which 10 women took diuretics (Table 2).

Table 2. Number of doped athletes from 2007 to 2017 breakdown by substance and by gender

\begin{tabular}{|c|c|c|c|c|c|c|c|c|c|c|c|c|c|c|c|c|c|}
\hline \multirow{2}{*}{ Sports Bodies 2007-2017 } & \multicolumn{2}{|c|}{7} & \multirow[t]{2}{*}{ 8-10 } & \multicolumn{2}{|c|}{11} & \multicolumn{2}{|c|}{12} & \multicolumn{2}{|c|}{13} & \multicolumn{2}{|c|}{14} & \multicolumn{2}{|c|}{15} & \multicolumn{2}{|c|}{16} & \multicolumn{2}{|c|}{17} \\
\hline & $\mathbf{M}$ & $\mathbf{F}$ & & $\mathbf{M}$ & $\mathbf{F}$ & $\mathbf{M}$ & $\mathbf{F}$ & $\mathbf{M}$ & $\mathbf{F}$ & $\mathbf{M}$ & $\mathbf{F}$ & $\mathbf{M}$ & $\mathbf{F}$ & $\mathbf{M}$ & $\mathbf{F}$ & $\mathbf{M}$ & $\mathbf{F}$ \\
\hline Cannabinoids & 17 & 5 & & 12 & 2 & 20 & 1 & 9 & 1 & 2 & 1 & 5 & 0 & 4 & 0 & 3 & 0 \\
\hline Stimulants & 11 & 1 & & 8 & 5 & 9 & 4 & 4 & 0 & 16 & 0 & 5 & 0 & 4 & 0 & 10 & 0 \\
\hline Diuretics and masking agents & 5 & 4 & & 17 & 3 & 7 & 6 & 6 & 0 & 17 & 10 & 2 & 4 & 2 & 3 & 4 & 1 \\
\hline Anabolic agents & 3 & 0 & & 14 & 2 & 5 & 1 & 20 & 1 & 23 & 0 & 14 & 0 & 3 & 2 & 27 & 1 \\
\hline hormones and related substances & 3 & 0 & & 3 & 0 & 7 & 1 & 11 & 0 & 16 & 0 & 3 & 0 & 4 & 0 & 2 & 0 \\
\hline Corticosteroids & 2 & 0 & & 8 & 2 & 3 & 0 & 5 & 1 & 5 & 3 & 3 & 3 & 7 & 0 & 3 & 2 \\
\hline beta blockers & 1 & 0 & & & & 1 & 0 & & & 4 & 0 & & & & & & \\
\hline beta agonists & & & & 4 & 0 & 1 & 0 & 1 & 1 & 2 & 1 & 1 & 0 & 2 & 1 & 2 & 1 \\
\hline Narcotics & & & & & & & & & & 1 & 0 & & & & & & \\
\hline Hormonal and metabolic modulators & & & & & & & & & & & & 0 & 1 & 0 & 1 & 2 & 0 \\
\hline
\end{tabular}

\section{Discussion}

The athletes can improve the effectiveness of using unconventional methods to improve sports performance in a Team Sport (Montesano \& Mazzeo, 2018). The physical abilities of athletes-distinguished in coordination and conditioning abilities-are always evaluated according to their performance and their success both as individual and as a team (Montesano, Tafuri, \& Mazzeo, 2013).

Therefore, Doping or taking substances for the purpose of enhancing sports performance has a long history. Drug use has always been associated with men. Lots of researches demonstrate that in the past the consumption of drugs by women experienced more severe social disapproval from men. In the early era of modern sport scholars and practitioners are paying an increasing attention to gender diversity. The injection of drugs by men was even tolerated (Buccelli, Della Casa, Paternoster, Niola, \& Pieri, 2016; Bobzean, DeNobrega, \& Perrotti, 2014; Mazzeo et al., 2018).

Therefore, there are lots of studies based on the male population, as well as anti-doping tests mainly focus on males. But, over time, a wide use of drugs has also been observed in women. In fact, the 2015 European Drug Report of the European Monitoring Centre for Drugs and Drug Addiction indicated that approximately one in four users entering treatment are women and one out of every five drug-related-deaths is female (Buccelli et al., 2016; Calatayud, Alcaide, Zurian, \& Benavent, 2007; Striegel, Ulrich, \& Simon, 2010).

However, gender differences in drug intake depend on several factors: genetics, physiology, anatomy, and sociocultural expectations and experiences (Badoud et al., 2011; Mazzeo, 2016; Santamaria, 2016). Moreover, gender also influences the course and treatment of substance use disorder. Gender differences are in personal and psychological characteristics.
Women, unlike men, tend to pass more quickly from occasional consumption to addiction than men, they are looking for increasingly high doses of drugs, especially during periods of abstinence, tend to fall into recidivism, and are less likely to seek treatment (Stella et al., 2003).

At any rate, the effect gratification linked to the intake of drugs associates men and women (Heggie, 2010). Drugs, in fact, give pleasant sensations or help the subject in his activity. Moreover, people (equally men or women) with an ego orientation don't want to improve their self but only give the appearance of improvement (Tavani et al., 2012); they are aware that only with their own abilities can't excel over others. They, also, hate defeat and therefore, look for the victory in any way (Duda, Chi, Newton, Walling, \& Catley, 1995; Duda, \& Nicholls, 1992).

The International Olympic Committee (IOC) established a Medical Commission (IOC-MC) which had the task of designing a strategy to combat the misuse of drugs in Olympic Sport (Mazzeo et al., 2016). Moreover, in sportsmen and women, the first step to prevent the recourse to the doping is to extend the knowledge on it and in particular on its dangerous effects on health (Altavilla, Mazzeo, D'Elia, \& Raiola, 2018, D’elia, Mazzeo, \& Raiola, 2018; Mazzeo \& Raiola, 2018). Studies, should be carried out in order to improve our knowledge of the safety profile of drug use in male or female athletes, due to conflicting outcomes between gender differences.

\section{Acknowledgements}

There are no acknowledgements.

\section{Conflict of Interest}

The authors declare that there are no conflicts of interest.

Received: 01 November 2018 | Accepted: 28 December 2018 | Published: 01 February 2019 


\section{References}

Altavilla, G., Mazzeo, F., D’Elia, F., \& Raiola, G. (2018). Physical commitment and specific work for each role in an elite soccer team. Journal of Physical Education and Sport, 18(2), 570-574. doi:10.7752/jpes.2018.02083

Badoud, F., Guillaume, D., Boccard J., Grata, E., Saugy, M., Rudaz, S., \& Veuthey, J.L. (2011). Analytical aspect in doping control: Challenges and perspectives. Forensic Science International, 213, 49-61. doi: 10.1016/j. forsciint.2011.07.024.

Bobzean, S.A.M., DeNobrega, A.K., \& Perrotti, L.I. (2014). Sex differences in the neurobiology of drug addiction. Experimental Neurology, 259, 64-74. doi: 10.1016/j.expneurol.2014.01.022.

Botre, F. (2008). New and old challenges of sport drug testing. J Mass Spectrom, 43, 903-7. doi: 10.1002/jms.1455.

Buccelli, C., Della Casa, E., Paternoster, M., Niola, M., \& Pieri, M. (2016). Gender differences in drug abuse in the forensic toxicological approach. Forensic Science International, 265, 89-95. doi: 10.1016/j.forsciint.2016.01.014.

Calatayud, V.A., Alcaide, G.G., Zurian, J.C., \& Benavent, R.A. (2007) Consumption of anabolic steroids in sport, physical activity and as a drug of abuse: an analysis of the scientific literature and areas of research. Br J Sports Med, 42, 103-9. doi: 10.1136/bjsm.2007.036228

D'elia, F., Mazzeo, F., \& Raiola, G. (2018). The core curriculum in the university training of the teacher of physical education in Italy. Journal of Human Sport and Exercise, 13, S413-S420. doi:10.14198/jhse.2018.13.Proc2.25

Duda, J.L., \& Nicholls, J.C. (1992). Dimension of achievement motivation in schoolwork and sport. Journal of Educational Psychology, 84(3), 290-99. doi: 10.1037/0022-0663.84.3.290

Duda, J.L., Chi, L., Newton, M.L., Walling, M.D., \& Catley, D. (1995). Task and Ego Orientation and Intrinsic Motivation in Sport. Int. J. Sport. Psychol., 26, 40-63.

Dvorak, J., Baume, N., Botré, F., Broséus, J., Budgett, R., Frey, WO., Geyer, H., et al. (2014). Time for change: a roadmap to guide the implementation of the World Anti Doping Code 2015. Br J Sport Med, 0, 1-6.

Frenger, M., Pitsch, W., \& Emrich, E. (2016). Sport-Induced Substance Use-An Empirical Study to the Extent within a German Sports Association. PloS one, 11(10), e0165103. doi:10.1371/journal.pone.0165103

Heggie, V. (2010). Testing sex and gender in sports; reinventing, reimagining and reconstructing histories. Endeavour, 34(4), 157-63.

Kayser, B., Mauron, A., \& Miah, A. (2005). Viewpoint: Legalisation of Perfomance- Enhancing Drugs. The Lancet, 366, S21. doi: 10.1016/ S0140-6736(05)67831-2

Marclay, F., Mangin, P., Margot, P., \& Saugy, M. (2013). Perscpetcives for Forensic Intelligence in anti doping:Thinking outside of the box. Forensic Science International, 229, 133-144. doi: 10.1016/j.forsciint.2013.04.009

Mazzeo, F. (2016). Drug abuse in elite athletes: Doping in sports. Sport Science, 9(2), 34-41.

Mazzeo, F. \& Raiola, G. (2018). An investigation of drugs abuse in sport performance. Journal of Human Sport and Exercise, 13, S309-S319. doi:10.14198/jhse.2018.13.Proc2.15

Mazzeo, F., Monda, V., Santamaria, S., Nigro, E., Valenzano, A., Villano, I. Cibelli, G., Messina, A., \& Messina, G. (2018). Antidoping program: An important factor in the promotion and protection of the integrity of sport and athlete's health. Journal of Sports Medicine and Physical Fitness, 58(7-8), 1135-1145. doi: 10.23736/S0022-4707.17.07722-2

Mazzeo, F., Santamaria, S., Monda, V., Tafuri, D., Dalia, C., Varriale, L., De Blasio, S., Esposito, V., Messina, G., \& Monda, M. (2016). Dietary supplements use in competitive and non-competitive boxer: An exploratory study. Biology and Medicine, 8(4), art. no. 1000294. doi:10.4172/09748369.1000294

Mazzeo, F., Monda, M., Messina, G., Santamaria, S., Messina, A., Montesano, M., Monda, V., \& Tafuri, D. (2016a). Doping in Italy: An analysis of its spread in ten years. Biology and Medicine, 8(1), 1000263. doi:10.4172/09748369.1000263

Moller, V. \& Dimeo, P. (2014). Anti-doping - the end of sport International Journal of Sport Policy and Politics, 6(2) 259-272. doi: 10.1080/19406940.2013.798740

Montesano, P. \& Mazzeo, F. (2018). Pilates improvement the individual basics of service and smash in volleyball. Sport Mont, 16(3), 25-30. doi:10.26773/smj.181005

Montesano, P., Tafuri, D., \& Mazzeo, F. (2013). Improvement of the motor performance difference in athletes of weelchair basketball. Journal of Physical Education and Sport, 13(3), 362-370. doi:10.7752 jpes.2013.03058

Overbye, M., Knudsen, M.L., \& Pfister, G. (2013). To dope or not to dope: Elite athletes' perceprions of doping deterrents and incentive. Performace Enhancement \& Health, 2, 119-134. doi: 10.1016/j.peh.2013.07.001

Sjoqvist, F., Garle, M. \& Rane, A. (2008). Use of doping agents, particularly anabolic steroids, in sports and society. Lancet, 371(9627), 1872-82. doi: 10.1016/S0140-6736(08)60801-6.

Stella, L., de Novellis, V., Vitelli, M.R., Capuano, A., Mazzeo, F., Berrino, L., Rossi, F., \& Filippelli, A. (2003). Interactive role of adenosine and dopamine in the opiate withdrawal syndrome. Naunyn Schmiedebergs Arch Pharmacol, 368(2), 113-118. https://doi.org/10.1007/s00210-003-0773-9

Strano, R.S., \& Botrè, F. (2011). Prevalence of illicit drug use among the Italian athlete population with special attention on drugs of abuse: A 10 yea review. J. Sports Sci, 29(5), 471-6. doi: 10.1080/02640414.2010.543915.

Striegel, H., Ulrich, R., \& Simon, P. (2010). Randomized response estimates for doping and illicit drug use in elite athletes. Drug Alcohol Depend., 106(23), 230-2. doi: 10.1016/j.drugalcdep.2009.07.026

Tavani, A., Colombo, P., Scarpino, V., Zuccaro, P., Pacifici, R., \& La Vecchia, C. (2012). Beliefs on and attitude toward doping use among athletes: an Italian Survey. IJPH, 9(4), e8669-1-7. doi: https://doi.org/10.2427/8669

Thevis, M. \& Scänzer, W. (2014). Analytical approaches for the detection of emerging therapeutics and non -approved drugs in human doping controls. J Pharm Biomed Anal, 101, 66-83. doi: 10.1016/j.jpba.2014.05.020

Valkenburg, D., de Hon, O., \& van Hilvoorde, I. (2014). Doping control, providing whereabouts and the importance of privacy for elite athletes. Int. J. Drug Policy, 25, 212-8. doi: 10.1016/j.drugpo.2013.12.013.

World Anti-Doping Agency (WADA) (2010). A Brief History of Anti-doping. Retrived: http://www.wada-ama.org/en/About- WADA/History/A-Brief-History-of-Anti-Doping/ 